\title{
Tolerância à dessecação de sementes de espécies de Eugenia
}

\author{
Liliana Ferreira Delgado(1) e Claudio José Barbedo ${ }^{(1)}$
}

\begin{abstract}
(1)Instituto de Botânica, Seção de Sementes e Melhoramento Vegetal, Av. Miguel Stéfano, no 3687, Água Funda, CEP 04301-012, São Paulo, SP. E-mail: lilianadelgado@ig.com.br, claudio.barbedo@pesquisador.cnpq.br
\end{abstract}

\begin{abstract}
Resumo - O objetivo deste trabalho foi avaliar a tolerância à dessecação de sementes de seis espécies frutíferas nativas de Eugenia (E. brasiliensis Lam., E. cerasiflora Miq., E. involucrata DC., E. pyriformis Camb., E. umbelliflora Berg. e E. uniflora L.) e fornecer subsídios para a conservação do poder germinativo dessas sementes durante o armazenamento. As sementes foram submetidas a secagens progressivas, em estufa $\left(40^{\circ} \mathrm{C}\right)$ e em câmaras com sílica-gel $\left(25^{\circ} \mathrm{C}\right)$, até $10 \%$ de água. Após cada secagem, as sementes foram avaliadas quanto ao teor de água e germinação. Observou-se relação significativa entre a diminuição do teor de água e a redução do poder germinativo, independentemente do processo de secagem. Apesar de diferenças nos limites de tolerância à dessecação das sementes das diferentes espécies, a redução do teor de água para valores inferiores a $45 \%$ sempre prejudicou a germinação dessas sementes, que perderam a capacidade germinativa quando o teor de água foi inferior a $15 \%$.
\end{abstract}

Termos para indexação: Myrtaceae, recalcitrante, secagem, frutífera, tropical.

\section{Desiccation tolerance of seeds of species of Eugenia}

\begin{abstract}
The objective of this work was to evaluate the desiccation tolerance of seeds of six fruit species of Eugenia (E. brasiliensis Lam., E. cerasiflora Miq., E. involucrata DC., E. pyriformis Camb., E. umbelliflora Berg. and E. uniflora L.) aiming to provide information for the conservation of the germinability of these seeds during storage. Seeds were dried continuously in oven $\left(40^{\circ} \mathrm{C}\right)$ or closed chambers with silica gel $\left(25^{\circ} \mathrm{C}\right)$ until $10 \%$ water content. After drying, samples of the seeds were analyzed for water content and germination. As water content decreased, seeds lost viability, independently of the drying method. Seeds from each species differed on sensitivity to desiccation, but all seeds were intolerant to levels lower than $45 \%$ water content and lost viability at levels lower than $15 \%$.

Index terms: Myrtaceae, recalcitrant, drying, fruit, tropical.
\end{abstract}

\section{Introdução}

As espécies brasileiras de Myrtaceae compreendem diversas plantas arbóreas e arbustivas que, em razão da qualidade de suas frutas, podem ser utilizadas na produção de frutos para consumo in natura ou para indústria, na produção de fármacos e na arborização urbana (Lorenzi, 1992, 1998; Donadio \& Moro, 2004; Barbedo et al., 2005).

Muitas espécies são de uso limitado, por ausência de informações sobre o manejo de suas sementes (Barbedo et al., 1998). Essa limitação é verificada em algumas espécies do gênero Eugenia, tais como E. uniflora (pitangueira), E. brasiliensis (grumixameira), E. involucrata (cerejeira-do-rio-grande) e E. pyriformis (uvaieira), entre outras.

Entre as espécies domesticadas, E. uniflora é um arbusto de vasta e expressiva distribuição (Legrand
\& Klein, 1969). Apresenta compostos potencialmente farmacológicos de efeito anti-inflamatório, diurético, antihipertensivo, anti-triglicérides e hipoglicêmico (Pepato et al., 2001), além de seus frutos serem comercializados na forma de sucos e distribuídos no mercado nacional.

E. brasiliensis é uma arvoreta característica e exclusiva da mata pluvial atlântica no Sul do Brasil, bastante rara (Legrand \& Klein, 1969) e ornamental. Os frutos são de sabor agradável, e podem ser consumidos in natura ou na forma de conservas e doces.

E. involucrata é uma árvore de vasta distribuição nas submatas mais desenvolvidas, em solos úmidos e não muito acidentados (Legrand \& Klein, 1969). Por não se desenvolver tanto em altura e ter copa ampla, tem potencial como árvore ornamental (Barbedo et al., 2005). 
E. pyriformis mede de 5 a $15 \mathrm{~m}$ de altura, tem frutos globosos de aproximadamente $2 \mathrm{~cm}$ (Legrand \& Klein, 1969), com mesocarpo comestível de sabor adocicado e acidulado, usados na produção de sucos, vinagre, vinho e licor (Andrade \& Ferreira, 2000).

Entre as espécies não domesticadas, E. umbelliflora Berg. (guapê) é um arbusto exclusivo da restinga litorânea, com vasta e expressiva dispersão pelo litoral; e E. cerasiflora Miq. (guamirim) é uma árvore exclusiva da mata pluvial da encosta atlântica no Sul do Brasil, bastante rara, e ocorre principalmente nos fundos de vales, inícios das encostas, nas chapadas e encostas pouco acidentadas (Legrand \& Klein, 1969).

Sementes de várias espécies brasileiras de Eugenia apresentam elevado teor de água (entre 40 e $70 \%$ ) quando os frutos são dispersos e são consideradas sensíveis à dessecação (Barbedo et al., 1998; Anjos \& Ferraz, 1999; Andrade \& Ferreira, 2000; Andrade et al., 2003), o que acarreta problemas na viabilidade e no potencial de armazenamento dessas sementes.

Segundo Lorenzi (1992), as sementes de E. involucrata e de $E$. uniflora possuem baixa longevidade (30 dias) quando as condições de armazenamento não são controladas. Porém, em câmara fria, Barbedo et al. (1998) conseguiram armazenar as sementes de E. involucrata por até 120 dias e Maluf et al. (2003) reduziram o teor de água para 53\%, por até 180 dias.

Em sementes de E. pyriformis, Andrade \& Ferreira (2000) conseguiram assegurar a viabilidade das sementes por até 60 dias, mas observaram perda de viabilidade quando o teor de água foi reduzido para valores inferiores a 14\%. Andrade et al. (2003) também observaram estreita relação entre germinação e teor de água em sementes de E. dysenterica DC. (cagaiteira), que perderam totalmente a viabilidade quando o teor de água foi reduzido para 18 a $22 \%$.

A qualidade fisiológica de sementes de E. stipitata ssp. sororia McVaugh (araçá-boi) também foi afetada pela redução do teor de água, pois o teor crítico de água, quando se inicia a perda da viabilidade, pode estar entre 58,8 e $47,1 \%$, e seu teor letal de água, a partir do qual não ocorre germinação, próximo a $25,8 \%$ (Gentil \& Ferreira, 1999).

Assim, sementes de Eugenia podem ter a velocidade de deterioração reduzida, desde que sejam estudadas as variáveis que aceleram essa deterioração.
O objetivo deste trabalho foi avaliar a tolerância à dessecação de sementes de seis espécies frutíferas nativas de Eugenia e fornecer subsídios para a conservação do poder germinativo dessas sementes durante o armazenamento.

\section{Material e Métodos}

Frutos maduros de Eugenia brasiliensis de dois biótipos (frutos amarelos e frutos roxos), E. pyriformis e E. involucrata foram coletados em árvores na Reserva Biológica e Estação Experimental de Moji-Guaçu, SP $\left(22^{\circ} 15^{\prime} \mathrm{S}-22^{\circ} 16^{\prime} \mathrm{S}\right.$ e $47^{\circ} 8^{\prime} \mathrm{W}-$ $47^{\circ} 12^{\prime} \mathrm{W}$ ); os de E. uniflora, em propriedade privada na região norte da Cidade de São Paulo, SP $\left(23^{\circ} 28^{\prime} \mathrm{S}-\right.$ $23^{\circ} 29^{\prime} \mathrm{S}$ e $\left.46^{\circ} 35^{\prime} \mathrm{W}-46^{\circ} 38^{\prime} \mathrm{W}\right)$; os de E. cerasiflora, no Jardim Botânico de São Paulo, em São Paulo, SP $\left(23^{\circ} 38^{\prime} \mathrm{S}\right.$ e $\left.46^{\circ} 37^{\prime} \mathrm{W}\right)$, e os de E. umbelliflora no Parque Estadual da Ilha do Cardoso, em Cananéia, SP $\left(25^{\circ} 04^{\prime} \mathrm{S}\right.$ e $\left.47^{\circ} 54^{\prime} \mathrm{W}-47^{\circ} 55^{\prime} \mathrm{W}\right)$. As coletas foram realizadas de outubro a dezembro de 2004, em cerca de cinco a dez árvores por espécie.

Os frutos foram macerados manualmente e lavados em água corrente, sobre peneiras para a separação das sementes. Em seguida, as sementes foram envolvidas em tecido de algodão para retirada do excesso de umidade superficial e, então, selecionadas e acondicionadas em sacos de cloreto de polivinila (PVC) de $0,4 \mathrm{~mm}$ de espessura, com pequenas perfurações, em geladeira a $8^{\circ} \mathrm{C}$, até o início dos experimentos (no máximo sete dias após as coletas).

Após a retirada de amostras dos lotes, denominadas controle, o restante das sementes foi submetido a dois tipos de secagem: intermitente em estufa e contínua em sílicagel. A secagem intermitente em estufa foi realizada a $40 \pm 2^{\circ} \mathrm{C}$, com circulação forçada de ar, e as sementes foram colocadas em prateleiras forradas com sombrite, em camadas simples sem sobreposição. Foram alternados períodos de 8 horas de secagem por 16 horas de repouso. A secagem contínua em sílica-gel foi realizada dentro de recipientes de vidro com fechamento hermético, em temperatura de $22 \pm 7^{\circ} \mathrm{C}$, sendo feita a troca da sílica-gel assim que $1 \mathrm{~cm}$ da camada mais superficial perdia sua coloração azul intensa. Periodicamente (a cada 2 horas em estufa e diariamente em sílica-gel) foram retiradas amostras de sementes para avaliação da qualidade. 
Amostras retiradas antes e no decorrer da secagem foram analisadas quanto ao teor de água e germinação. $\mathrm{O}$ teor de água das sementes, expresso em base úmida, foi avaliado conforme descrito nas Regras Internacionais para Análise de Sementes (Ista, 1985), por meio do método de estufa a $103 \pm 2^{\circ} \mathrm{C}$, durante 17 horas, com quatro repetições de cinco sementes cada.

O teste de germinação foi realizado em germinadores Marconi tipo MA400, com circulação interna de água, regulados para a temperatura constante de $25^{\circ} \mathrm{C}$ e luz contínua. O teste foi instalado em rolo de papel tipo Germitest, com duas folhas para a base e uma para cobertura (Brasil, 1992), pré-umedecidas, com quatro repetições de dez sementes. As avaliações foram realizadas a cada 15 dias, e foram consideradas a germinabilidade (protrusão de, no mínimo, $5 \mathrm{~mm}$ de raiz primária) e a germinação (sementes que produziram plântulas normais, ou seja, com sistema radicular e eófilos desenvolvidos e sem defeitos aparentes).

$\mathrm{O}$ delineamento experimental utilizado foi o inteiramente casualizado e os dados foram submetidos à análise de variância pelo teste $\mathrm{F}$, a $5 \%$ de probabilidade. Quando significativas, foram ajustadas regressões polinomiais e, quando necessário para correção da normalidade e da heterogeneidade, os dados foram transformados para arc sen (x) $)^{0,5}$ (Santana \& Ranal, 2004).

\section{Resultados e Discussão}

O teor de água das espécies estudadas foi bastante elevado, de 42,5 a 66,8\% (52,0\% para E. uniflora, 49,6\% para $E$. brasiliensis roxa e $47,2 \%$ para amarela, $58,2 \%$ para E. involucrata, $66,8 \%$ para E. pyriformis, $42,5 \%$ para E. umbelliflora e $62,8 \%$ para E. cerasiflora). Este fato é comum entre espécies do gênero Eugenia, como E. dysenterica DC. (47-53\%), segundo Andrade et al. (2003), E. stipitata ssp. sororia McVaugh $(58,8 \%)$, segundo Gentil \& Ferreira (1999) e E. rostrifolia Legr. (43\%) segundo Santos et al. (2004). O teor de água das sementes de Eugenia involucrata de 58,2\% foi muito próximo ao valor encontrado por Barbedo et al. (1998), de $63,4 \%$ e por Maluf et al. (2003), de 60,3\%. O teor de água das sementes de E. brasiliensis roxa de 46,9\% também foi muito próximo ao de $48,9 \%$ encontrado por Kohama et al. (2006).

A secagem das sementes de todas as espécies e em todos os teores foi mais rápida em estufa do que em sílica-gel. Em média, os períodos necessários para se atingirem valores próximos a 40, 30, 20 e 10\% de água foram, respectivamente, $8,56,95$ e 160 horas (aproximadamente $0,26 \%$ por hora), em estufa e 192, 288,456 e 624 horas (aproximadamente $0,08 \%$ por hora), em sílica.

A secagem das sementes de todas as espécies estudadas prejudicou tanto a germinabilidade quanto a produção de plântulas normais, independentemente do método de secagem utilizado (Figuras 1 a 7). O nível letal de água, ou seja, aquele a partir do qual não ocorreu germinação, foi muito próximo para todas as espécies de Eugenia estudadas, ficando entre 15 e 20\%. Esta sensibilidade à dessecação
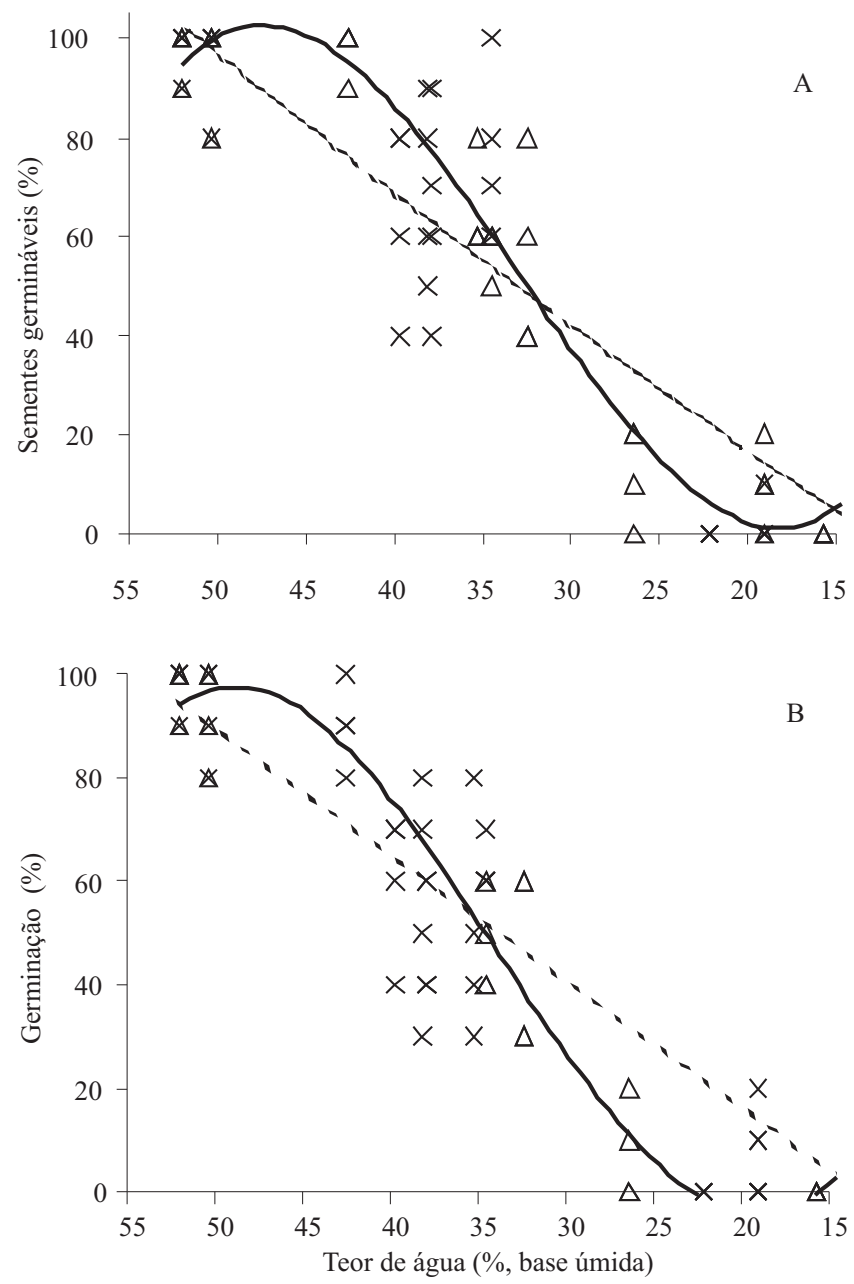

Figura 1. Regressões $(\mathrm{p}<0,05)$ obtidas para germinabilidade (A) e germinação de sementes (B) de Eugenia uniflora, em função de diferentes teores de água, obtidos por meio de secagem em estufa, a $40 \pm 2^{\circ} \mathrm{C}(\Delta,-)$, e em sílica-gel, a $22 \pm 7^{\circ} \mathrm{C}$ $(\mathrm{X},---) . \mathrm{Y}_{\mathrm{A}, \Delta}=169,6590-21,1355 \mathrm{X}+0,8007 \mathrm{X}^{2}-0,0081 \mathrm{X}^{3}$, $\mathrm{r}^{2}=0,9393 ; \mathrm{Y}_{\mathrm{A}, \mathrm{X}}=-123,2958+7,4216 \mathrm{X}+0,0615 \mathrm{X}^{2}, \mathrm{r}^{2}=0,8844$; $Y_{B, \Delta}=143,6130-17,8030 X+0,6592 X^{2}-0,0064 X^{3}, r^{2}=0,9395$; $\mathrm{Y}_{\mathrm{B}, \mathrm{X}}=-57,7440+3,0073 \mathrm{X}, \mathrm{r}^{2}=0,8447$. 
situa tais sementes entre as recalcitrantes, de acordo com a classificação de Roberts (1973). Contudo, há autores que consideram a sensibilidade à dessecação das sementes recalcitrantes como fator quantitativo, o que caracteriza níveis de recalcitrância (Berjak \& Pammenter, 2000; Walters, 2000) e permite categorizar as sementes recalcitrantes de acordo com o potencial hídrico mínimo suportado (Walters, 2000).

Quanto ao teor de água a partir do qual houve perda de viabilidade, pôde-se verificar diferença na sensibili-
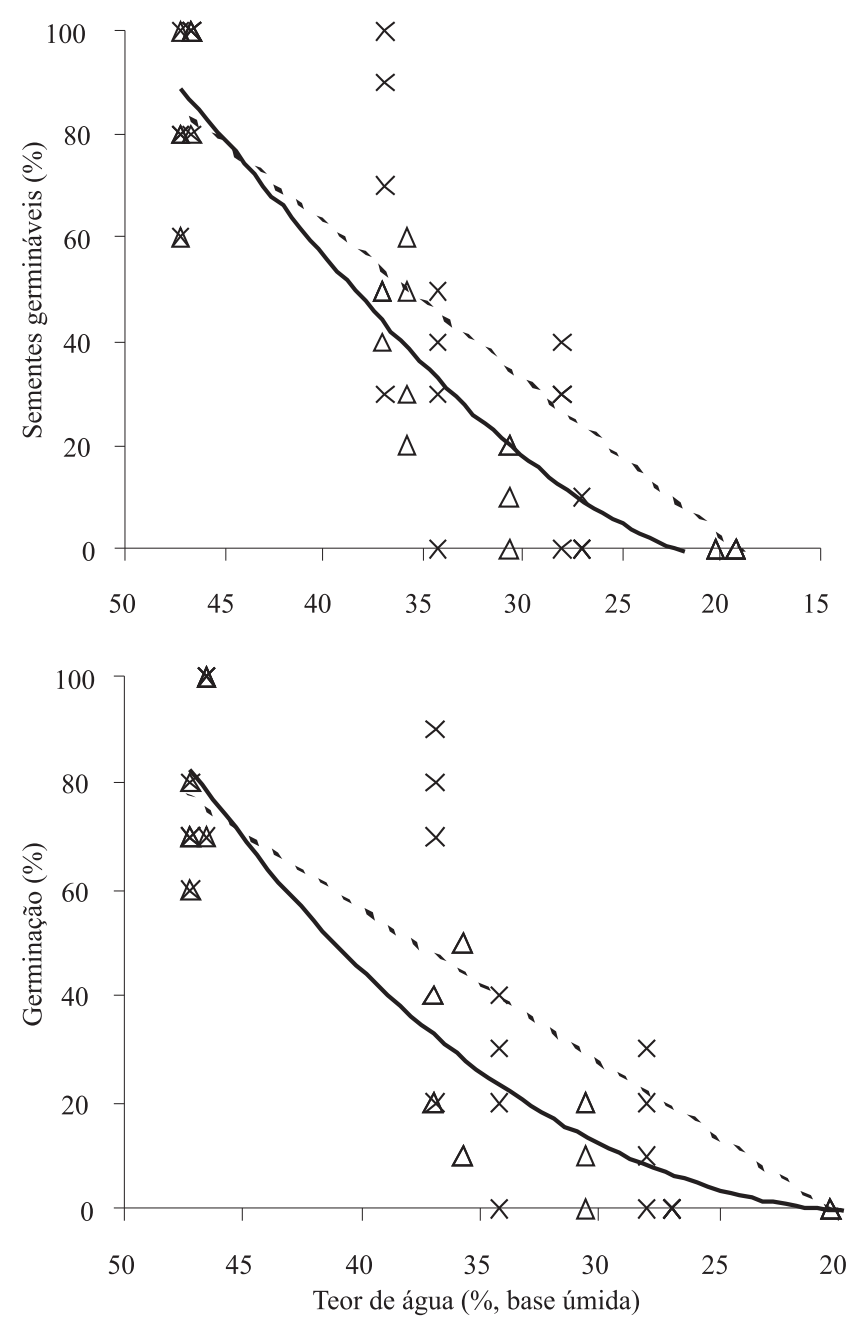

Figura 2. Regressões $(\mathrm{p}<0,05)$ obtidas para germinabilidade (A) e germinação de sementes (B) de Eugenia brasiliensis, biótipo roxo, em função de diferentes teores de água, obtidos por meio de secagem em estufa, a $40 \pm 2^{\circ} \mathrm{C}(\Delta, \longrightarrow)$, e em sílicagel, a $22 \pm 7^{\circ} \mathrm{C}(\mathrm{X},---)$. $\mathrm{Y}_{\mathrm{A}, \Delta}=-0,7309-1,5508 \mathrm{X}+0,0734 \mathrm{X}^{2}$, $\mathrm{r}^{2}=0,9172 ; \mathrm{Y}_{\mathrm{A}, \mathrm{X}}=-91,5935+3,8861 \mathrm{X}, \mathrm{r}^{2}=0,7137$ $\mathrm{Y}_{\mathrm{B}, \Delta}=41,2861-4,2459 \mathrm{X}+0,1084 \mathrm{X}^{2}, \mathrm{r}^{2}=0,8742$; $\mathrm{Y}_{\mathrm{B}, \mathrm{X}}=-97,9502+3,8777 \mathrm{X}, \mathrm{r}^{2}=0,6959$. dade à perda de água das sementes entre diferentes espécies, que permitiu identificar três grupos distintos.

As sementes mais sensíveis à dessecação foram as de Eugenia pyriformis (Figura 5), que apresentaram início de perda da viabilidade em teor de água superior e próximo a $65 \%$. O teor letal, que foi de $15 \%$ para as sementes dessa espécie, por sua vez, foi muito próximo ao observado por Andrade \& Ferreira (2000), entre 14 e $20 \%$.
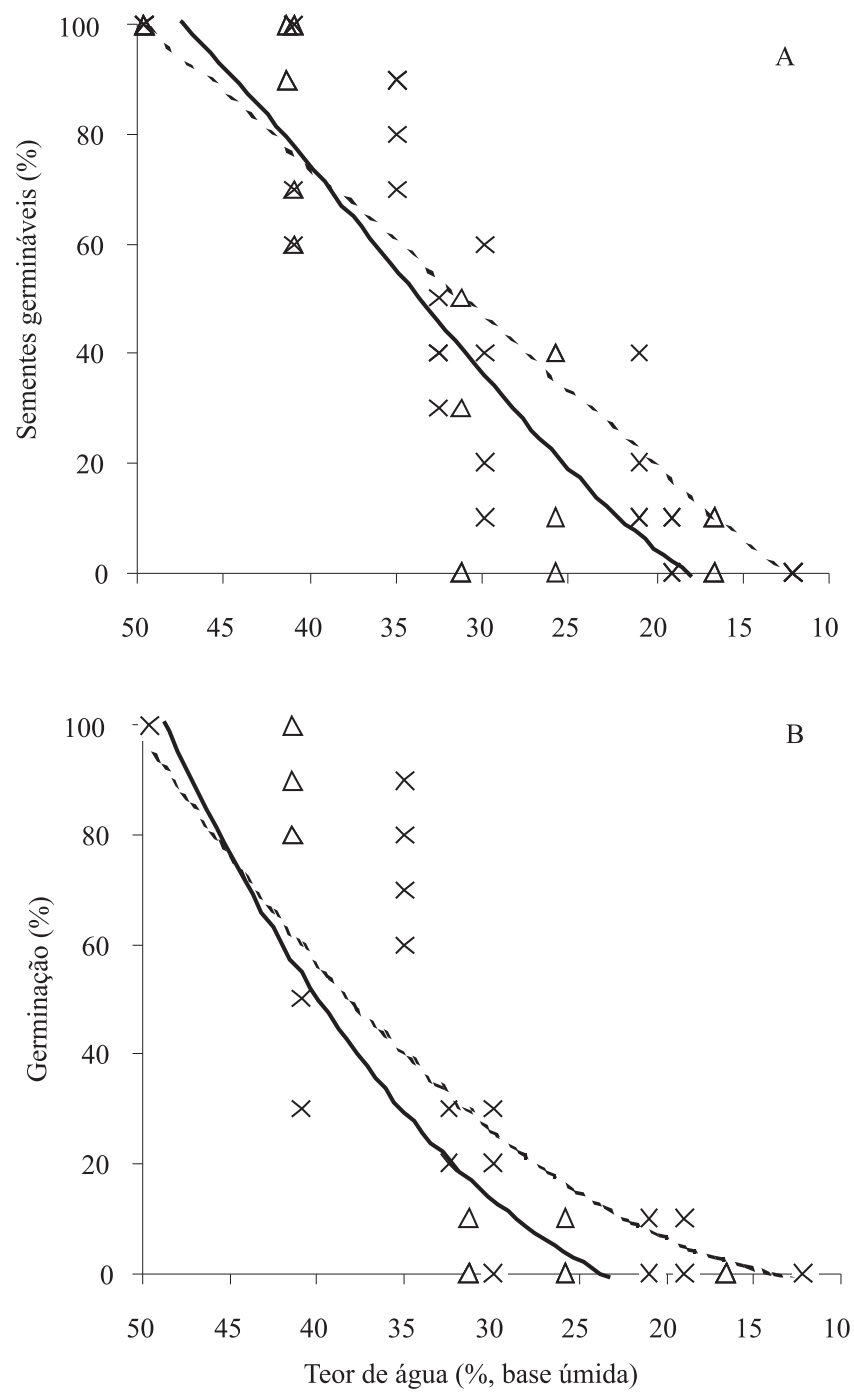

Figura 3. Regressões ( $\mathrm{p}<0,05)$ obtidas para germinabilidade (A) e germinação de sementes (B) de Eugenia brasiliensis, biótipo amarelo, em função de diferentes teores de água, obtidos por meio de secagem em estufa, a $40 \pm 2^{\circ} \mathrm{C}(\Delta,-)$, e em sílica-gel, a $22 \pm 7^{\circ} \mathrm{C}(\mathrm{X},---) . \mathrm{Y}_{\mathrm{A}, \Delta}=240,7042-27,3296 \mathrm{X}+0,9511 \mathrm{X}^{2}-0,0092 \mathrm{X}^{3}$, $\mathrm{r}^{2}=0,8093 ; \mathrm{Y}_{\mathrm{A}, \mathrm{X}}=-52,2591+3,1958 \mathrm{X}, \mathrm{r}^{2}=0,8684 ; \mathrm{Y}_{\mathrm{B}, \Delta}=206,0886$ $-22,2683 \mathrm{X}+0,6955 \mathrm{X}^{2}-0,0058 \mathrm{X}^{3}, \mathrm{r}^{2}=0,8419 ; \mathrm{Y}_{\mathrm{B}, \mathrm{X}}=-9,4691-$ $0,2659 \mathrm{X}+0,0483 \mathrm{X}^{2}, \mathrm{r}^{2}=0,7862$. 
As sementes de E. uniflora, E. brasiliensis e E. involucrata (Figuras 1 a 4) situaram-se em posição intermediária quanto à sensibilidade à dessecação, com início de perda da viabilidade em teor de água em aproximadamente 45-50\%. Os valores obtidos para sementes de E. brasiliensis foram muito próximos aos obtidos por Kohama et al. (2006), os quais realizaram secagem a $36^{\circ} \mathrm{C}$ e observaram teor crítico próximo a $43,1-48,9 \%$.
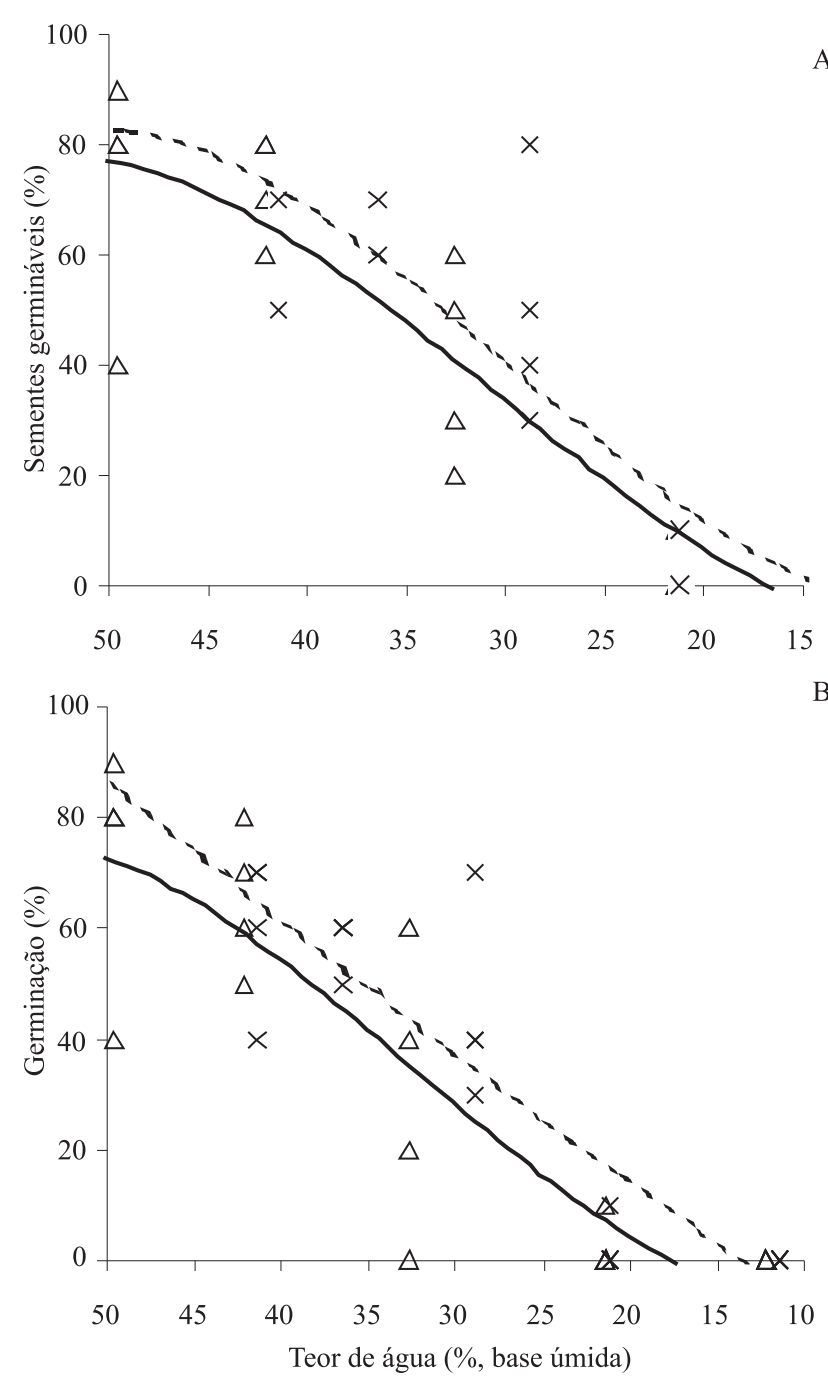

Figura 4. Regressões $(\mathrm{p}<0,05)$ obtidas para germinabilidade (A) e germinação de sementes (B) de Eugenia involucrata, em função de diferentes teores de água, obtidos por meio de secagem em estufa, a $40 \pm 2^{\circ} \mathrm{C}(\Delta,-)$, e em sílica-gel, a $22 \pm 7^{\circ} \mathrm{C}$ $(\mathrm{X},---) . \mathrm{Y}_{\mathrm{A}, \Delta}=40,2038-6,6342 \mathrm{X}+0,3010 \mathrm{X}^{2}-0,0030 \mathrm{X}^{3}$, $\mathrm{r}^{2}=0,8588 ; \mathrm{Y}_{\mathrm{A}, \mathrm{X}}=7,2351-2,9070 \mathrm{X}+0,2025 \mathrm{X}^{2}-0,0023 \mathrm{X}^{3}$, $\mathrm{r}^{2}=0,8376 ; \mathrm{Y}_{\mathrm{B}, \Delta}=50,9949-7,5560 \mathrm{X}+0,3116 \mathrm{X}^{2}-0,0030 \mathrm{X}^{3}$, $\mathrm{r}^{2}=0,8220 ; \mathrm{Y}_{\mathrm{B}, \mathrm{X}}=-28,092+1,9907 \mathrm{X}+0,0063 \mathrm{X}^{2}, \mathrm{r}^{2}=0,7952$.
Em relação às sementes de E. involucrata, os valores obtidos foram próximos aos de $51 \%$ obtidos por Barbedo et al. (1998), que realizaram secagem à sombra, e por Maluf et al. (2003), com secagem em estufa a 30,40 e $50^{\circ} \mathrm{C}$. O teor letal de água obtido por esses autores (31-41\%), no entanto, foi superior aos obtidos neste trabalho.

O terceiro grupo, das menos sensíveis à dessecação, foi formado pelas sementes das espécies não domesticadas
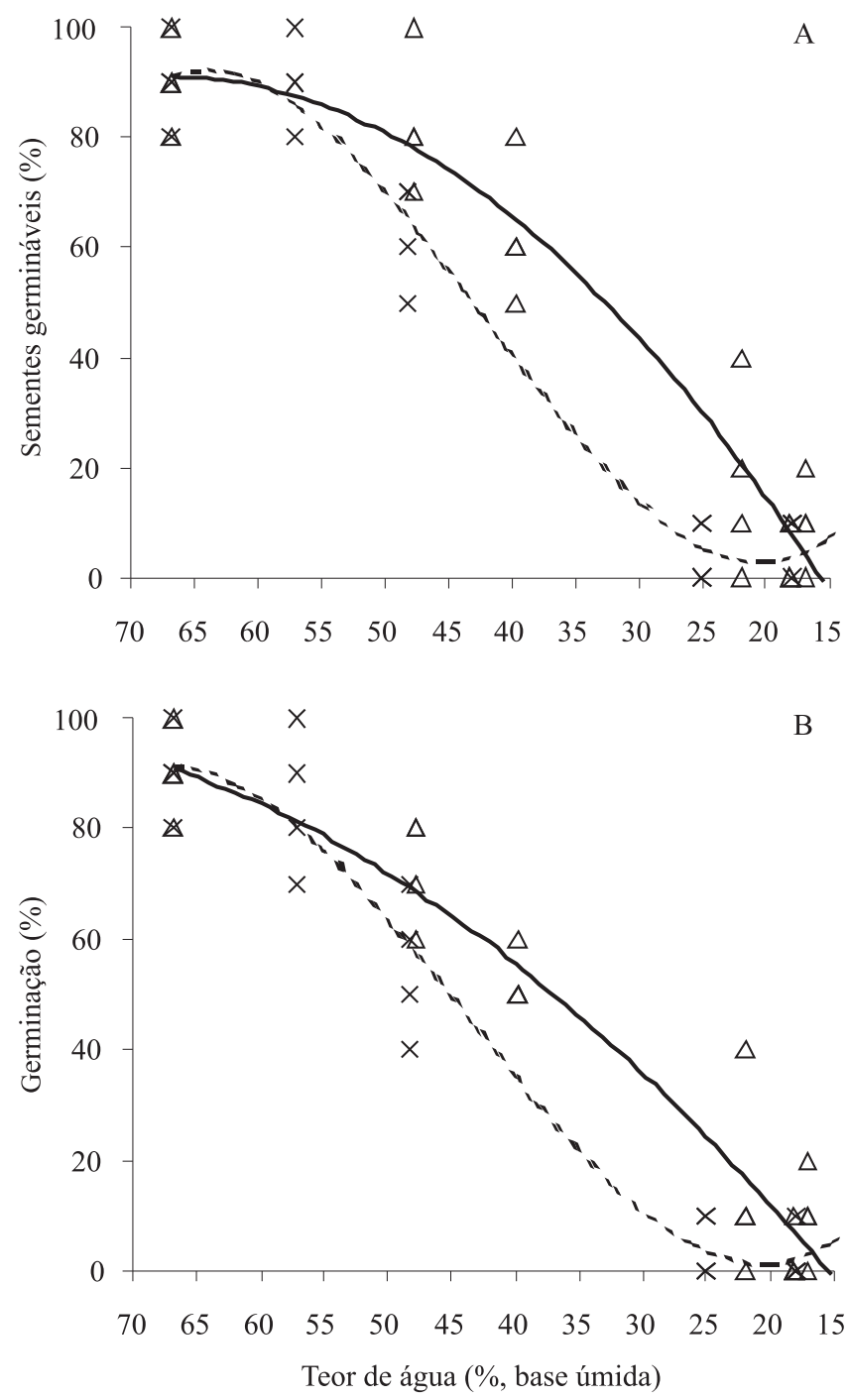

Figura 5. Regressões $(p<0,05)$ obtidas para germinabilidade (A) e germinação de sementes (B) de Eugenia pyriformis, em função de diferentes teores de água, obtidos por meio de secagem em estufa, a $40 \pm 2^{\circ} \mathrm{C}(\Delta,-)$, e em sílica-gel, a $22 \pm 7^{\circ} \mathrm{C}$ $(\mathrm{X},---) . \mathrm{Y}_{\mathrm{A}, \Delta}=-64,3638+4,6298 \mathrm{X}-0,0345 \mathrm{X}^{2}, \mathrm{r}^{2}=0,9165$; $\mathrm{Y}_{\mathrm{A}, \mathrm{X}}=80,5774-8,5145 \mathrm{X}+0,2743 \mathrm{X}^{2}-0,0022 \mathrm{X}^{3}, \mathrm{r}^{2}=0,9259$; $\mathrm{Y}_{\mathrm{B}, \Delta}=-46,5301+3,2918 \mathrm{X}-0,0185 \mathrm{X}^{2}, \mathrm{r}^{2}=0,9275 ; \mathrm{Y}_{\mathrm{B}, \mathrm{X}}=69,2784$ $-7,3687 X+0,2339 X^{2}-0,0018 X^{3}, r^{2}=0,9493$. 
E. umbelliflora e E. cerasiflora, cujo início da perda de viabilidade ocorreu quando o teor de água ficou em torno de $45 \%$ (Figuras 6 e 7 ).

A velocidade de secagem é considerada fundamental para a avaliação do limite de tolerância à dessecação das sementes. Berjak \& Pammenter (2000) consideraram que quanto mais rápida a velocidade de secagem,
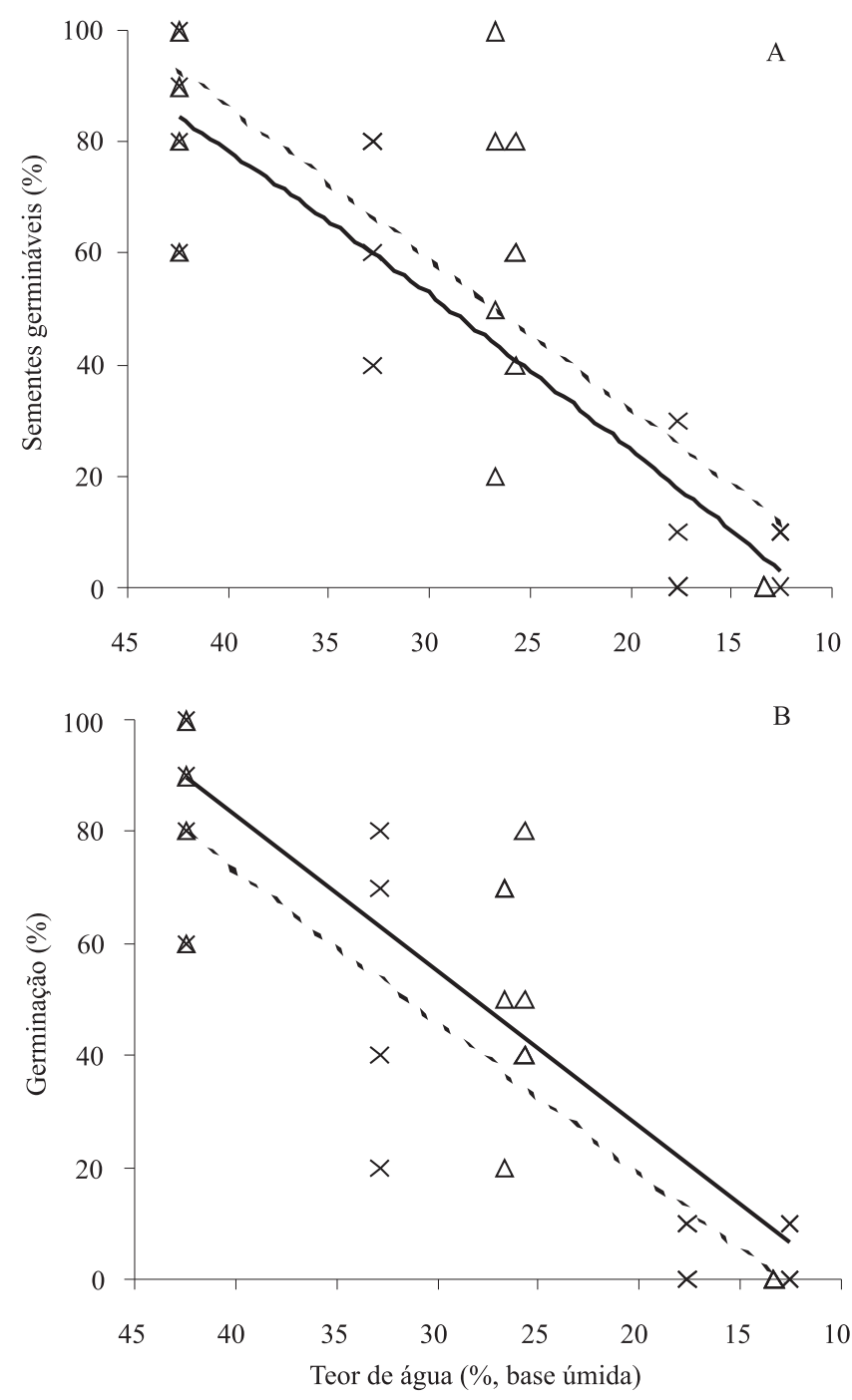

Figura 6. Regressões $(\mathrm{p}<0,05)$ obtidas para germinabilidade (A) e germinação de sementes (B) de Eugenia umbelliflora, em função de diferentes teores de água, obtidos por meio de secagem em estufa, a $40 \pm 2^{\circ} \mathrm{C}\left(\Delta, \rightarrow\right.$, e em sílica-gel, a $22 \pm 7^{\circ} \mathrm{C}$ $(\mathrm{X},---) . \mathrm{Y}_{\mathrm{A}, \Delta}=-104,2852+9,4124 \mathrm{X}-0,1181 \mathrm{X}^{2}, \mathrm{r}^{2}=0,7399$; $\mathrm{Y}_{\mathrm{A}, \mathrm{X}}=-30,7750+2,7334 \mathrm{X}, \mathrm{r}^{2}=0,8461 ; \mathrm{Y}_{\mathrm{B}, \Delta}=-27,7437+$ $2,7585 X, r^{2}=0,7946 ; Y_{B, X}=-35,6711+2,7995 X, r^{2}=0,8285$. maior o grau de desidratação suportado pela semente. Contudo, Rosa et al. (2005) observaram que as menores reduções na qualidade fisiológica de sementes de Coffea canephora ocorreram em secagem de velocidade intermediária ( $0,5 \%$ por hora), em comparação com as secagens rápida $(1,25 \%$ por hora $)$ e lenta $(0,15 \%$ por hora).
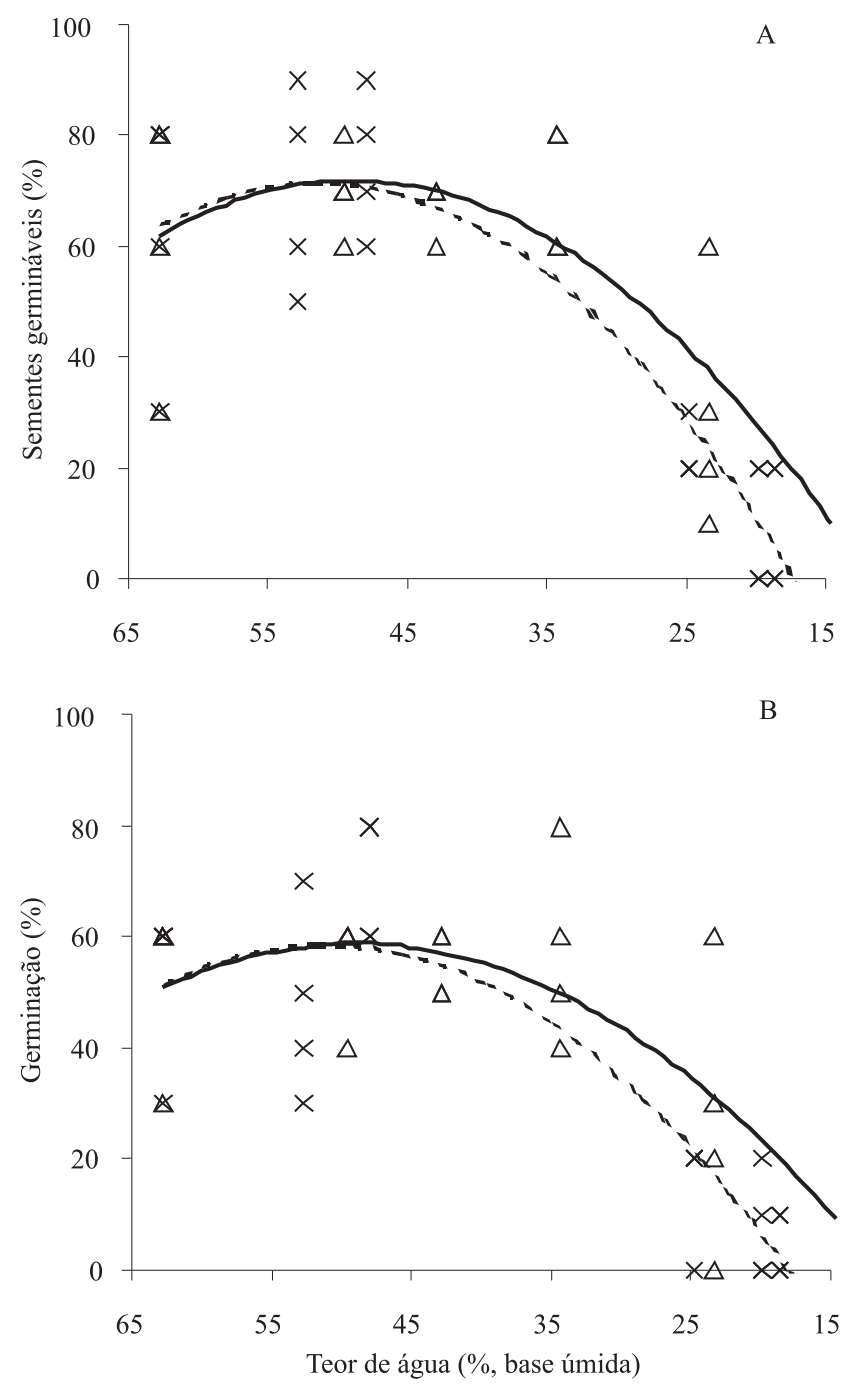

Figura 7. Regressões $(\mathrm{p}<0,05)$ obtidas para germinabilidade (A) e germinação de sementes (B) de Eugenia cerasiflora, em função de diferentes teores de água, obtidos por meio de secagem em estufa, a $40 \pm 2^{\circ} \mathrm{C}(\Delta,-)$, e em sílica-gel, a $22 \pm 7^{\circ} \mathrm{C}$ $(\mathrm{X},---) . \mathrm{Y}_{\mathrm{A}, \Delta}=-53,7821+5,1313 \mathrm{X}-0,0524 \mathrm{X}^{2}, \mathrm{r}^{2}=0,7847$; $\mathrm{Y}_{\mathrm{A}, \mathrm{X}}=-90,1222+6,2924 \mathrm{X}-0,0613 \mathrm{X}^{2}, \mathrm{r}^{2}=0,8108$; $\mathrm{Y}_{\mathrm{B}, \Delta}=-41,6866+4,0960 \mathrm{X}-0,0417 \mathrm{X}^{2}, \mathrm{r}^{2}=0,7086$; $Y_{B, X}=-81,0438+5,4668 X-0,0535 X^{2}, r^{2}=0,7775$. 
Os resultados de perda de viabilidade com a redução do teor de água das sementes das seis espécies estudadas não apresentaram uniformidade quanto ao método de secagem utilizado, ora com aumento da sensibilidade à dessecação para a secagem em estufa (mais rápida), ora em sílica (mais lenta). Na secagem mais lenta, as sementes permanecem por maior período com níveis de hidratação que permitem a ocorrência de reações prejudiciais, até mesmo as provocadas por radicais livres, que pode causar sérios danos à estrutura das membranas (Pammenter et al., 1998; Berjak \& Pammenter, 2000). Por sua vez, a elevação da temperatura de secagem, como a ocorrida na secagem em estufa, comumente acelera a velocidade de secagem, mas pode resultar em alterações nas sementes, principalmente enzimáticas, que acarreta prejuízos.

Walters (2000) considerou que, para tolerar a dessecação, a semente necessita de diferentes sistemas de proteção a cada nível de remoção de água e, dessa forma, teria seu grau de tolerância condicionado ao tipo de água removida em cada etapa e a presença desses sistemas. De maneira geral, as sementes das seis espécies de Eugenia brasileiras estudadas apresentaram início da perda de viabilidade em teor de água de 45 a $60 \%$. Nessa faixa, a água presente nas sementes poderia apresentar as propriedades da água tipo 5, descrita por Vertucci (1990) e mencionada por Vertucci \& Farrant (1995), Castro et al. (2004) e Marcos Filho (2005). As características deste tipo de água, retida com tensões inferiores a -1,5 MPa, correspondem às apresentadas por soluções diluídas; não se liga às macromoléculas e é suficiente até mesmo para que ocorra germinação. A remoção de maior quantidade de água, com teor reduzido a níveis entre 41 e $20 \%$, poderia modificar as propriedades da água remanescente, que passaria à água dos tipos 3 e 4, ocupando espaços intercapilares entre as macromoléculas, sem interagir com estas, ou associada a sítios hidrofóbicos, com intensa atividade respiratória e deterioração acelerada (Vertucci \& Farrant, 1995; Castro et al., 2004; Marcos Filho, 2005), eventos que provavelmente ocorreram nas sementes de Eugenia sp. estudadas.

Os teores entre 15 e $20 \%$ que representaram teores letais de água, por sua vez, caracterizariam a água presente como tipo 2 (Vertucci \& Farrant, 1995), ou seja, água ligada a sítios hidrofílicos, e não ocorre mais síntese de proteínas e de ácidos nucléicos. Este grau de hidratação favorece o armazenamento de sementes ortodoxas, mas depende da presença de um sistema que garanta a integridade das membranas, a dediferenciação de organelas, a presença de mecanismos antioxidativos, a formação do estado vítreo, entre outros sistemas necessários à aquisição de tolerância à dessecação (Castro et al., 2004; Faria et al., 2005). Dessa forma, é provável que sementes das espécies de Eugenia estudadas não apresentem quaisquer dos fatores descritos como fundamentais para a tolerância à dessecação.

O conhecimento do teor de água a partir do qual se inicia a perda da viabilidade das sementes de espécies frutíferas brasileiras de Eugenia obtido neste trabalho pode fornecer importante dado para posteriores trabalhos de armazenamento, como constatado para outras espécies (Gentil, 2003). Contudo, deve-se considerar o possível aumento na atividade metabólica das sementes recalcitrantes no início da remoção de água, conforme os estudos de ultra-estrutura descritos por Berjak $\&$ Pammenter (2000), que poderiam prejudicar a conservação dessas sementes no armazenamento, conforme observado em sementes de E. involucrata (Barbedo et al., 1998).

\section{Conclusões}

1. Sementes de Eugenia uniflora, E. brasiliensis, E. involucrata, E. pyriformis, E. umbelliflora e E. cerasiflora são sensíveis à redução do teor de água para valores inferiores a $45 \%$ e, acima deste valor, apresentam diferentes graus de sensibilidade à dessecação.

2. As sementes de E. pyriformis são as mais sensíveis à dessecação, e as de E. umbelliflora e E. cersaiflora, as menos sensíveis.

3. Sementes das espécies de Eugenia perdem a viabilidade em teores de água de 15 a $20 \%$.

\section{Agradecimentos}

Ao CNPq, pela bolsa de produtividade concedida a Claudio José Barbedo; à Fapesp, pelo auxílio financeiro; ao Instituto Florestal de São Paulo e ao Instituto de Botânica, pela permissão para as coletas; à Dra. Rita de Cássia Leone Figueiredo Ribeiro e ao Dr. José Márcio Rocha Faria, pela revisão crítica do artigo. 


\section{Referências}

ANDRADE, A.C.S.; CUNHA, R.; SOUZA, A.F.; REIS, R.B.; ALMEIDA, K.L. Physiological and morphological aspects of seed viability of a neotropical savannah tree, Eugenia dysenterica DC. Seed Science and Technology, v.31, p.125-137, 2003.

ANDRADE, R.N.B.; FERREIRA, A.G. Germinação e armazenamento de sementes de uvaia (Eugenia pyriformis Camb.) Myrtaceae. Revista Brasileira de Sementes, v.22, p.118-125, 2000.

ANJOS, A.M.G.; FERRAZ, I.D.K. Morfologia, germinação e teor de água das sementes de araçá-boi (Eugenia stipitata ssp. sororia). Acta Amazonica, v.29, p.337-348, 1999.

BARBEDO, A.S.C.; BIANCHI, C.G.; KELLER, L.R.; ORTEGA, M.G.; ORTEGA, S.E.H. Manual técnico de arborização urbana. 2.ed. São Paulo: PMSP-SVMA, 2005. 45p.

BARBEDO, C.J.; KOHAMA, S.; MALUF, A.M.; BILIA, D.A.C. Germinação e armazenamento de diásporos de cerejeira (Eugenia involucrata DC. - Myrtaceae) em função do teor de água. Revista Brasileira de Sementes, v.20, p.184-188, 1998.

BERJAK, P.; PAMMENTER, N. What ultrastructure has told us about recalcitrant seeds. Revista Brasileira de Fisiologia Vegetal, v.12, p.22-55, 2000.

BRASIL. Ministério da Agricultura e Reforma Agrária. Regras para análise de sementes. Brasília: SNDA/DNDV/CLAV, 1992. 365p.

CASTRO, R.D.; BRADFORD, K.J.; HILHORST, H.W.M. Desenvolvimento de sementes e conteúdo de água. In: FERREIRA, A.G.; BORGHETTI, F. (Org.). Germinação: do básico ao aplicado. Porto Alegre: Artmed, 2004. p.51-67.

DONADIO, L.C.; MORO, F.V. Potential of Brazilian Eugenia (Myrtaceae) - as ornamental and as a fruit crop. Acta Horticulturae, v.632, p.65-68, 2004.

FARIA, J.M.R.; BUITINK, J.; LAMMEREN, A.A.M. van; HILHORST, H.W.M. Changes in DNA and microtubules during loss and re-establishment of desiccation tolerance in germinating Medicago truncatula seeds. Journal of Experimental Botany, v.56, p.2119-2130, 2005.

GENTIL, D.F.O. Conservação de sementes de Myrciaria dubia (H.B.K.) McVaugh. 2003. 51p. Tese (Doutorado) - Escola Superior de Agricultura Luiz de Queiroz, Piracicaba.

GENTIL, D.F.O.; FERREIRA, S.A.N. Viabilidade e superação da dormência em sementes de araçá-boi (Eugenia stipitata ssp. sororia). Acta Amazonica, v.29, p.21-31, 1999.

ISTA. International rules for seed testing. Seed Science and Technology, v.13, p.356-513, 1985.
KOHAMA, S.; MALUF, A.M.; BILIA, D.A.C.; BARBEDO, C.J. Secagem e armazenamento de sementes de Eugenia brasiliensis Lam. (grumixameira). Revista Brasileira de Sementes, v.28, p.72-78, 2006.

LEGRAND, C.D.; KLEIN, R.M. Flora ilustrada catarinense. Itajaí: Herbário Barbosa Rodrigues, 1969. 216p.

LORENZI, H. Árvores brasileiras: manual de identificação e cultivo de plantas arbóreas nativas do Brasil. Nova Odessa: Plantarum, 1992. $352 \mathrm{p}$.

LORENZI, H. Árvores brasileiras: manual de identificação e cultivo de plantas arbóreas nativas do Brasil. Nova Odessa: Plantarum, 1998. v.2. $368 \mathrm{p}$.

MALUF, A.M.; BILIA, D.A.C.; BARBEDO, C.J. Drying and storage of Eugenia involucrata DC. seeds. Scientia Agricola, v.60, p.471-475, 2003.

MARCOS FILHO, J. Fisiologia de sementes de plantas cultivadas. Piracicaba: Fealq, 2005. 495p.

PAMMENTER, N.W.; GREGGAINS, V.; KIOKO, J.I.; WESLEYSMITH, J.; BERJAK, P.; FINCH-SAVAGE, W.E. Effects of differential drying rates on viability retention of recalcitrant seeds of Ekebergia capesis. Seed Science Research, v.8, p.463-471, 1998.

PEPATO, M.T.; FOLGADO, V.B.B.; KETTELHUT, I.C.; BRUNETTI, I.L. Lack of antidiabetic effect of a Eugenia jambolana leaf decoction on rat streptozotocin diabetes. Brazilian Journal of Medical and Biological Research, v.34, p.389-395, 2001.

ROBERTS, E.H. Predicting the storage life of seed. Seed Science and Technology, v.1, p.499-514, 1973.

ROSA, S.D.V.F. da; BRANDÃO JÚNIOR, D. da S.; VON PINHO, E.V.R.; VEIGA, A.D.; SILVA, L.H. de C. Effects of different drying rates on the physiological quality of Coffea canephora Pierre seeds. Brazilian Journal of Plant Physiology, v.17, p.199-205, 2005.

SANTANA, D.G.; RANAL, M. Análise da germinação: um enfoque estatístico. Brasília: Ed. Universidade de Brasília, 2004. 248p.

SANTOS, C.M.R.; FERREIRA, A.G.; ÁQUILA, M.E.A. Características de frutos e germinação de sementes de seis espécies de Myrtaceae nativas do Rio Grande do Sul. Ciência Florestal, v.14, p.13-20, 2004.

VERTUCCI, C.W. Calorimetric studies in the state of water in seed tissues. Biophysical Journal, v.58, p.1463-1471, 1990.

VERTUCCI, C.W.; FARRANT, J.M. Acquisition and loss of desiccation tolerance. In: KIGEL, J.; GALILI, G. (Ed.). Seed development and germination. New York: M. Dekker, 1995. p.237-271.

WALTERS, C. Levels of recalcitrance in seeds. Revista Brasileira de Fisiologia Vegetal, v.12, p.7-21, 2000.

Recebido em 17 de maio de 2006 e aprovado em 30 de outubro de 2006 